\title{
Psicología social ¿para qué?
}

\author{
SOCIAL PSYCHOLOGY. WHAT FOR?
}

Dr. Juan Soto-Ramírez (juansotoram@hotmail.com) Universidad Autónoma Metropolitana, Unidad Iztapalapa (Ciudad de México, México)

\begin{abstract}
Doing research involves a minimum set of responsibilities. One of them is to ask why do research? Today researchers and students do not ask about it. They assume they have to do research as mandatory. Research becomes a means and not an end. This paper is an overview of social psychology in Mexico (some statistical data is provided). It shows three aspects of how social psychology is addressed and some critical reflections that could be useful for those engaged in research in social psychology.
\end{abstract}

Key words: research, evaluation, problem, analysis, distinction.

\section{Resumen}

Hacer investigación implica un conjunto de responsabilidades mínimas. Una de ellas es preguntarse ¿para qué hacer investigación? En el mundo actual los investigadores y los estudiantes no suelen preguntárselo. Suponen que deben hacer investigación como una obligación. Esto hace que la investigación se convierta en un medio y no en un fin. En este texto se brinda un panorama general de la psicología social en México recurriendo a algunos datos estadísticos. Posteriormente se abordan tres aspectos de la forma en que se hace psicología social y se ofrecen algunas reflexiones críticas que podrían ser útiles para quienes se dedican a la investigación en psicología social.

Palabras clave: investigación, evaluar, problematizar, analizar, distinguir.

\section{Introducción}

Es demasiado común que, de forma recurrente, tanto en los medios impresos como en los medios electrónicos se publiquen artículos donde se haga referencia a las listas de los empleos "mejor" y "peor" pagados en diversas partes del mundo. Es habitual también que casi siempre se tome como referencia a los Estados Unidos de América para ilustrar a los públicos sobre lo que se gana en aquel país y lo que se gana en el suyo. Y parece ser que a ningún profesional de la psicología social se le ha ocurrido hacer una investigación sobre el impacto que puede tener este tipo de notas en las personas. Sería bastante conspiranoico (1) suponer que la publicación de este tipo de notas tiene un objetivo específico: como influir en la toma de decisiones entre quienes están tratando de elegir una carrera a estudiar o entre aquellos que están tratando de dilucidar a qué se dedicarán en la vida. En dichas listas de los empleos "mejor" y "peor" pagados, existen dos constantes. La primera es que no se especifica el procedimiento metodológico a través del cual se obtuvieron los resultados. De tal forma que un anestesiólogo puede aparecer en la cima del top 10 de un país y un piloto aviador o naval puede ocupar el mismo puesto en otro. 
En México, de acuerdo con el Observatorio Laboral (2), que es un sitio en internet de la Secretaría del Trabajo y Previsión Social y que proporciona información sobre las características y el comportamiento de las ocupaciones y las profesiones más representativas en México, hasta el mes de abril del 2013, las carreras cuyos ocupados recibieron mayor ingreso promedio durante el último trimestre de acuerdo con la Cuarta Encuesta Nacional de Ocupación y Empleo, de mayor a menor salario fueron: 1. Ciencias de la tierra y de la atmósfera; 2. Filosofía y ética; 3. Minería y extracción; 4. Finanzas, banca y seguros; 5. Ingenierías de vehículos, de motor, barcos y aeronaves; 6 . Economía; 7. Servicios de transporte; 8 . Historia y arqueología; 9. Silvicultura; y 10. Medicina. Es obvio que este panorama sería alentador para cualquier estudiante de filosofía que mira cómo en su país la matrícula universitaria de estudiantes de filosofía adelgaza lenta y constantemente. Según este sitio de internet, un filósofo gana, en promedio, USD $\$ 1,200.00$ al mes. Estas cifras pueden hacer pensar a cualquiera que alguien está mintiendo. Bien los filósofos o bien los administradores del sitio.

De acuerdo con el mismo sitio y para dicho trimestre, psicología fue la sexta carrera con mayor número de ocupados. Número que ascendió a casi 222 mil personas. De las cuales se indicó que el $64.5 \%$ de ellas deben tener empleo y deben dedicarse a algo relacionado con lo que estudiaron. Psicología fue la séptima carrera con mayor porcentaje de mujeres ocupadas y ascendió a 71.6\%. Esto querría decir, entre otras cosas, que haber estudiado psicología y ser hombre no es una buena combinación de indicadores para elegir a alguien como un buen partido, por ejemplo. Es preferible el filósofo.

La segunda constante que podemos encontrar en las famosas listas de los empleos "mejor" y "peor" pagados es que, aunque la carrera de psicología llega a colarse ocasionalmente en el top 10, la psicología social, como tal, no lo hace jamás. Sea por desconocimiento o falta de sensibilidad de los sistemas clasificatorios, nuestra disciplina no se menciona. Es un lugar común para la mayor parte de los psicólogos sociales que después de decir lo que uno estudió o que estudia psicología social, a uno le pregunten ¿qué es la psicología social?, ¿qué estudia la psicología social?, ¿a qué se dedica un psicólogo social?, ¿hay trabajo para los psicólogos sociales?, etc. Y aunque es más fácil decir que uno es sociólogo para evitar preguntas de todo tipo, quienes se dan a la tarea de explicar qué hace, qué estudia y en qué trabaja un psicólogo social, muchas veces terminan dando detalles de lo que hacen ellos y no precisamente hablan de la disciplina como tal. Es cierto, "hablar de psicología social nos puede llevar a equívocos. El más común es creer que la psicología social pertenece al campo de la psicología” (Álvaro y Garrido 2003:45). Y por alguna razón se piensa que la psicología es como una especie de matriz de la cual se desprende una insospechada variedad de 'subgéneros' de la psicología. Algunos demasiado exóticos por cierto.

En los diarios donde se publican anuncios ofreciendo servicios y empleos, difícil o escasamente se puede encontrar alguno que diga "se solicita un psicólogo social". Y es que es cierto, aunque los historiadores de nuestra disciplina puedan presumir que sus orígenes se remontan a los inicios del siglo XX aproximadamente (3), tanto en los ámbitos académicos como en los no académicos se sabe poco de la psicología social y de esa diferencia entre psicología y psicología social. Incluso los profesionales de otras disciplinas suelen confundir la psicología social con la psicología o, lo que es más terrible, confunden a la psicología social con el psicoanálisis o la psicología clínica. Precisar que uno es psicólogo social y no un psicólogo a secas es una tarea nada ociosa. Clarificar esta diferencia entre los estudiantes debería ser una de las primeras actividades a las que podrían dedicarse los profesores de psicología social cada vez que inicien cursos. 


\section{Los psicólogos sociales no son los héroes de las historias sino los pertinaces de las mismas}

Tomás Ibáñez, un destacado psicólogo social de la Universidad Autónoma de Barcelona, en ese bonito texto titulado ¿Fondear la objetividad o navegar hacia el placer? precisó que: "el conocimiento que los psicólogos y psicólogas sociales hemos elaborado hasta el presente no ha tenido el suficiente carácter innovador, ni el suficiente poder dilucidador, ni la suficiente difusión social para conseguir impactar de manera significativa en la sociedad y alterar algunas de sus características. Pero no existen razones de principio para descartar que esto pueda ocurrir en un futuro" (2002:34).

Y es cierto. Después de más de una década de hacer esta afirmación, parece que la psicología social sigue sin haber conseguido 'impactar' de manera significativa en la sociedad y, en consecuencia, no podemos esperar que haya alterado algunas de sus características. Eso sí, a diferencia de lo que ocurría hace poco más de diez años al interior de las comunidades de psicólogos sociales, podemos decir que hoy en día existen más eventos como congresos, coloquios, encuentros, semanas, etc., que se organizan en torno a eso que llamamos psicología social. Cuando uno se percata que ya hubo un Segundo Congreso Internacional de Psicología de la Posmodernidad ya no tiene más remedio que sentirse anacrónico y rebasado por todo lo que ocurre alrededor. Sin embargo, esto no ha sido razón suficiente para clarificar entre las personas en general ¿qué es? o ¿a qué se dedica la psicología social?

Cuando a los niños se les hace la típica pregunta ¿qué quieres ser de grande? Pueden responder que quieren ser bomberos, médicos, policías, astronautas, cocineras, maestras, etc. En México incluso hay niños que responden que les gustaría ser narcotraficantes. Pero no responden que les gustaría ser psicólogos sociales. La profesión como tal no parece ser un referente simbólico en los procesos básicos de la socialización. A menos que tengan por padre o madre a un psicólogo social y quisieran dedicarse a lo mismo, difícilmente los niños responderán que les gustaría dedicarse a la psicología social. La psicología social parece ser una profesión propia de 'tíos raros'. Y no es que los medios tengan la responsabilidad de darle difusión a las carreras y profesiones, pero de alguna manera hacen lo suyo. En las telenovelas, en las películas y en las series de televisión, los protagonistas suelen ser policías, médicos, detectives privados, militares, gente de negocios y hasta asesinos seriales, pero nunca psicólogos sociales. Hasta el momento. Y como ya lo dijo Tomás Ibáñez, "pero no existen razones de principio para descartar que esto pueda ocurrir en un futuro". Quizá los escritores y guionistas rectifiquen en algún momento de la historia.

Eso quiere decir que quizás a los que nos dedicamos a la psicología social nos pasó algo extraño en la vida y "está claro que si algunos de nosotros estamos comprometidos hoy con la investigación es más por un concurso de circunstancias que nos ha conducido en esta vía que por propia y deliberada decisión" (Ibáñez 2002:32). Salvo alguna extrañísima excepción, difícilmente algún psicólogo social podría decir que ya desde niño afirmaba que quería ser uno de ellos. Y sobra decir que en los niños existe mucha sensatez. Parece ser también que salvo algunas excepciones, pocos de los estudiantes que ingresan a la carrera de psicología social tienen una idea más o menos clara de lo que implica ser psicólogo social y en qué terrenos de reflexión y campos de la investigación se mueve la disciplina.

De acuerdo con el coordinador del Foro Consultivo Científico y Tecnológico (FCCyT) (4), en México solo 16 de cada 10 mil habitantes estudian algún tipo de posgrado, de los cuales menos de la mitad ingresan al denominado Sistema Nacional de Investigadores (SNI), mientras que del resto no se conoce cuál es su destino. No obstante, no se menciona cuántos de esos 16 estudiantes de posgrado logran concluir sus estudios ni cuántos de ellos logran titularse. Podemos suponer con lujo de certeza entonces que la cifra debe de irse reduciendo. 
En México existen alrededor de 1.300 programas certificados por el Programa Nacional de Posgrados de Calidad frente a los 10.000 programas que operan en todo el país. No es tarea fácil responder a la pregunta cuántos de esos programas son de psicología social. Según datos de la Academia Mexicana de Ciencias (5) del 2011, de cada 3.000 doctores que egresaban al año en México, sólo 1.000 lograban conseguir un empleo o la oportunidad para continuar con sus trabajos de investigación. Los datos que se pueden recabar de acuerdo con el Programa Nacional de Posgrados de Calidad indican que de esos cerca de 1.300 programas certificados, solo 17 son de psicología y están repartidos en 11 universidades de México. De esos 17 programas, 6 son de doctorado y los 11 restantes de maestría. Y es curioso, pero cuando uno ingresa "psicología social" como nombre del programa de posgrado, el motor de búsqueda informa que "no existen resultados". Pensar en la filosofía como opción sigue siendo una alternativa. Los datos anteriores parecen indicar una cosa. Y es que la psicología social, de acuerdo con el sistema de clasificación institucional a nivel científico y tecnológico, también se considera una rama o un campo de especialización de la psicología y, por ende, los programas se apegan a dichos lineamientos. Esto parece subrayar un hecho y es que la psicología social se lleva bien con 'ser pertinaz'. Si como lo señaló Randall Collins, nuestra singularidad es producto de nuestro tránsito a través de distintas cadenas de interacción, algo pudo habernos pasado en la vida que nos volvió pertinaces (2005:19).

\section{Hablar de psicología social}

Frente a este panorama, podríamos decir que no es fácil hablar de psicología social con alguien. Podríamos pensar que, en ese sentido, las sesiones de clase, los encuentros, los coloquios, los congresos, las semanas de psicología social, deben tener algo de terapéutico. Si a uno no le aplauden al terminar, por lo menos puede tener la sensación de que lo escucharon. Salvo que a los familiares o amigos les asalte una profunda curiosidad por saber qué es lo que opina el psicólogo social de la familia sobre algún tema en particular, la opinión de aquél quedará reservada para las memorias o las reflexiones personales que, con un poco de suerte, podrá discutir con sus alumnos y ya con muchísima más suerte podrá exponer en un evento de psicología social. Publicar dichas ideas (en una revista, por ejemplo), consabido es, resulta ser un lujo epistemológico. Pero quizá estas reflexiones son todavía demasiado optimistas. Sobre todo porque habría que dar por sentado que a los alumnos de psicología social les interesan las reflexiones personales de sus profesores. Situación que por ningún motivo está garantizada.

Vicente Verdú, aunque no es psicólogo social, ha expresado bastante bien una idea y es que: "los profesores, salvo alguna curiosa excepción, llegan a clase (fuera es otra cosa) como si emergieran de la profundidad de los tiempos e imparten los contenidos como médiums de alguna revelación casi atemporal" (2005:38). En el ámbito de la psicología social existen médiums de los 'predecesores' de la disciplina. También hay 'voces autorizadas' e 'intérpretes', oficiales y no oficiales, de los psicólogos sociales contemporáneos. Y así sucesivamente. "Ningún maestro será capaz de empezar desde atrás sin que los alumnos se duerman ininterrumpidamente. O se evadan. O no acudan" (Verdú 2005:37). Y podemos decir también con cierto lujo de certeza que "los planes de estudio pierden cada año, cada mes, cada día, tiempo y oportunidades para actualizarse. Los alumnos se aburren, fracasan o descreen en la universidad [...] su educación está teniendo lugar fuera de las clases, ante las mil pantallas, en sus dormitorios o en los cibercafés [...] Las clases tienen que ver poco o nada con sus intereses" (Verdú 2005:38), salvo casos raros.

Una de las tensiones contemporáneas esenciales para la psicología social parece ser que la realidad apunta hacia una dirección y sus tradiciones teóricas hacia otras muy distintas. Ésta es la crisis de la psicología social contemporánea. Que sus teorías apuntan hacia un horizonte muy distinto de lo que ocurre en 
nuestras sociedades. Que sus versiones son insuficientes para explicar los problemas contemporáneos de la sociedad. Y que, más aún, sus conceptos y definiciones son insuficientes frente a una realidad que continuamente está superando todos esos discursos, relatos y narraciones de manufactura psicosocial. Si los estudiantes deciden hacer una tesis sobre temas novedosos como la cibercultura o las redes sociales, lo más seguro es que: a) se topen con un médium de vieja estirpe que les pida que utilicen una teoría de la psicología social para apoyar sus observaciones; b) su asesor dé 'luz verde' al proyecto, pero poco tenga que aportar al proyecto porque difícilmente tiene un perfil en Facebook y mucho menos ha leído del tema; o c) el investigador termine convenciéndolos de que ése no es un tema propio de la psicología social y que será mejor que cambien de tema.

Mientras las tradiciones de pensamiento de la psicología social apuntan hacia un sitio lúgubre, las dinámicas sociales contemporáneas se mueven en múltiples y diversas direcciones. Esto se traduce, más o menos, en la imagen que casi todos conocemos. Mientras el profesor habla de G. H. Mead y su importancia para la psicología social, los estudiantes intercambian mensajes SMS sobre cómo les fue el fin de semana en la fiesta de música electrónica o en el bar. Y muy lejos están las reflexiones de Mead del mundo contemporáneo. De tal modo que ni siquiera existe una remota posibilidad de que, hablando de Mead, uno pueda hacer que los estudiantes aparten por unos segundos su mirada de la pantalla de su dispositivo móvil. Y esto no quiere decir que los profesores de psicología social deban ponerse una nariz de payaso para lograr captar la atención de sus respectivos alumnos, pero sí es un llamado de atención bastante pertinente a todos aquellos que por mirar el pasado han dejado de mirar el presente con todo y su riqueza cultural. Y también es un llamado de atención a los jóvenes estudiantes de psicología social porque es cierto que no se puede pretender ser un psicólogo social sin conocer a los clásicos de la disciplina. Michael Billig lo dijo ya de una forma más radical: "los psicólogos sociales ignoran su pasado, sobre todo con base en el supuesto de que, así como nadie pondría una rueda de una carroza en un moderno carro deportivo, tampoco debe uno insertar nociones precientíficas en una disciplina científica seria" (1987:32). Refiriéndose a lo que él denominó 'psicólogos anticuarios', él afirmó que "el anticuario no muestra desdén por el pasado" (Billig 1987:33). Y los estudiantes no deberían mostrar desdén por el pasado o por los clásicos de la psicología social. Pero lo cierto es que no han cultivado, en su mayoría, el espíritu del anticuario.

Herbert Blumer hace bastante tiempo llamó la atención sobre una situación, dijo que "una ciencia sin conceptos sería una creación fantástica" (1981:117). Y también señaló que los conceptos "son producto de la reflexión humana. No son entidades derivadas de una experiencia perceptual directa: sino que han nacido como concepciones derivadas de experiencias perceptuales directas que han resultado desconcertantes y problemáticas para el hombre" (Blumer 1981:120). Esto es importante por una cuestión: "las teorías no son elementos cosificados a los que haya que adscribirse necesariamente para dar cuenta de todos los problemas sociales. Su función es hacer inteligible la realidad social, una realidad que no es uniforme, ni estática, sino múltiple y cambiante" (Álvaro y Garrido 2003:47). Es cierto, la psicología social es un área de conocimiento más que "un conocimiento con un objeto de estudio específico" (Álvaro y Garrido 2003:47). Y es aquí donde encontramos otro punto importante para la discusión. Todavía hay quienes, al dar su propia definición de psicología social, afirman que ésta se encarga de estudiar esto o aquello. Como si a la psicología social le correspondiera una parcela de la realidad que le es propia por derecho epistemológico o casi ontológico. ¿Podemos explicar fenómenos contemporáneos con viejos conceptos? Si es así, ¿hasta dónde es posible hacerlo? ¿Resultan los viejos conceptos más que útiles, pertinentes para explicar las nuevas dinámicas del mundo contemporáneo? ¿Sería pertinente rechazar los viejos conceptos y recurrir a otros nuevos? Ninguna postura radical que 
apuntara en cualquiera de las dos direcciones resultaría pertinente. Sin embargo habría que tomar en cuenta algunas consideraciones no de utilidad sino de cierta relevancia.

\section{Problematizar}

La primera iría en el sentido de ¿cómo? y ¿qué? problematizar en materia de investigación psicosocial y tomar en cuenta que: "no basta con multiplicar el acoplamiento de criterios tomados de la experiencia común (piénsese en todos esos temas de investigación del tipo «el ocio de los adolescentes de un complejo urbanístico en la zona periférica del este de París») para construir un objeto que, producto de una serie de divisiones reales, sigue siendo un objeto común y no accede a la dignidad de objeto científico por el solo hecho de prestarse a la aplicación de técnicas científicas" (Bourdieu 1973:59).

Pareciera ser que mientras más técnica sea la definición del objeto de investigación, más sospechosa es su naturaleza. Un objeto dotado de realidad social no posee precisamente realidad sociológica, antropológica o psicosocial. Por ello es tan fácil suponer que el denominado bullying (acoso escolar) o la procrastination (procrastinación) no son sólo realidades inminentes que aquejan a niños y jóvenes alrededor de todo el mundo, sino que son problemas de los cuales los psicólogos deberían encargarse. Un sinfín de tesis y proyectos de investigación en psicología social responden a estas modas académicas, por lo que la construcción y la definición de objetos de investigación no responden ni mínimamente a una problemática teórica. Baste a cualquier interesado investigar los temas en torno a los cuales se construyen y definen los proyectos de investigación de titulación de los distintos grados académicos de su demarcación geográfica y académica para tener una idea más o menos precisa de cuáles son las modas intelectuales del momento y que definen lo que podríamos llamar el mainstream de la psicología social (6). Baste a cualquiera inscribirse a un congreso de psicología social y revisar los títulos de los trabajos de investigación que en aquél se presentan para darse cuenta de cuáles son los trending topics (7) de la disciplina para el grupo convocante de confederados. No pensar con los medios, ni su jerga discursiva, es un buen comienzo para realizar una problematización de la realidad con espíritu crítico.

Hace tiempo Umberto Eco llamó la atención sobre un fenómeno interesante al cual denominó 'moda cultural', que consiste en una propensión 'por estar al día'. Y señalaba que "por ello puede ser interesante seguir, a lo largo de una década, el nacimiento, permanencia y descomposición de una serie de modas culturales. Costumbres, citas, aberraciones periodísticas de diferente tipo atestiguan su permanencia, mientras que su desaparición da cuenta de la volubilidad de los jugadores cultos y de nuestra dolorosa incapacidad para hacer fructificar sugerencias e ideas, líneas de investigación, temáticas y problemáticas" (1984:97). Él se refirió al concepto de "alienación» y la forma en que fue utilizado hasta el cansancio. Utilización extendida que debilitó su significado 'intelectual' al pasar de ser un 'término venerable' a ser 'moneda corriente'. Explicó que una cultura especializada se defiende, precisamente, gracias a su carácter de impenetrabilidad. Agregó que: "no se necesita ser una vestal del saber para reconocer que el nacimiento y la difusión de una moda cultural siembran incomprensiones, confusiones, usos ilegítimos. Deploramos las modas culturales. Cualquiera que haya tratado seriamente conceptos que después se han puesto de moda habrá experimentado la incomodidad producida por el hecho de que toda palabra que haya usado no ha sido interpretada jamás según el contexto en que aparecía, sino agitada como estandarte, etiqueta, señal de tráfico" (Eco 1984:99).

Para ilustrar tal situación podemos referirnos al concepto 'teoría'. Cualquiera que haya tomado un breve curso de epistemología sabrá que el concepto se encuentra ligado, al menos desde una perspectiva positivista, a un conjunto de teoremas y leyes organizados sistemáticamente y sometidos a algún tipo de 
verificación. Y, sin embargo, es 'moneda corriente' escuchar a las personas decir: 'según mi teoría pasa esto o aquello' o 'tengo una teoría que...'. Lo cual pone en evidencia la forma laxa en que se utiliza dicho término. Eco, atinadamente señaló que: "puede ponerse de moda la palabra "relatividad», pero no las ecuaciones de Maxwell" (1984:99). Esto tiene que ver, según su punto de vista, con la 'divulgación'. Y cabe señalar que no emprendió una crítica de censura hacia esta labor tan importante para la ciencia, sino que solamente destacó que la divulgación tiene sus costos. Es decir, los términos y los conceptos, al ponerse en circulación, reclutan 'nuevos miembros' para los campos de especialización y en este andar, devienen banales. Esto nos ayuda a entender que el significado del 'dato cultural' que va del ámbito científico hacia el ámbito cotidiano va ganando trivialidad. Habría, entonces, conceptos o términos 'científicos' que se vuelven populares (y es preciso acotar que eso no ocurre con todos los términos ni con todos los conceptos 'científicos'). De hecho el lector puede hacer un inventario de la cantidad inimaginable de conceptos científicos con los cuales se topa en una simple conversación cotidiana y podría sorprenderse.

No obstante, esta propuesta deja de lado dos fenómenos interesantes y que también podríamos considerar como propios de las 'modas culturales'. En este andar, también encontraríamos otras dos situaciones: una tendría que ver con el hecho de que habría conceptos o términos que no podríamos catalogar de 'científicos', pero que se presentan o se piensan como tales y que se vuelven populares. Son tan populares que la gente no duda de su existencia. Los terminachos como 'inconsciente' o 'frustración' podrían resultar muy ilustrativos. En el mundo contemporáneo, la mayor parte de las personas cuyo pensamiento vive dominado por una especie de 'psicologismo' atroz, no duda de la idea de que posee inconsciente. Idea que es parecida a la de poseer un espíritu o una 'fuerza viva' dentro del cuerpo. 'Fuerza' de carácter indomable y traicionera, por cierto. A la gente no le interesa que le expliquen en qué parte del cuerpo se aloja exactamente ese 'inconsciente' ni cómo se forma o por qué se manifiesta de formas tan extrañas como en los sueños. Según Michel Onfray, el psicoanálisis no se presentó "como la hipótesis de un hombre, e incluso la ficción de un filósofo, sino como un bien común, una verdad de orden general. Pasaba por ser un descubrimiento, como el de América por Cristóbal Colón" (2010:23). Pocos se han atrevido a dudar de 'la validez científica del psicoanálisis', aunque no sea, propiamente dicho, un conocimiento científico en el sentido positivista del término.

La segunda situación que se deja de lado en relación con las 'modas culturales', es aquella que nos llevaría a pensar que hay conceptos o términos que en realidad son populares o que se vuelven de uso popular y que, gracias a su utilización cotidiana y bastante extendida, adoptan una fachada científica en tanto que, al convertirse en 'temas de investigación', atrapan investigadores y estudiantes despistados. Éste es el caso del concepto de 'narcocultura'. En México, en Colombia y en muchos otros países azorados por el tráfico de drogas, se utilizan palabras tan exóticas como narcotúnel, narcomanta, narcomensaje, narcoesposa, narcocorrido, narcoviolencia, narcopolítica, narcovenganza, narcofosa, narcoloqueaustedseleocurra, etc., para hacer alusión a todo lo que sucede cotidianamente entre los narcotraficantes. Esto ha dado pie a que muchas personas, académicos entre ellas, terminen por creer que existe la denominada narcocultura. Incluso se atreven a montar exposiciones en museos en torno a ello. Cualquiera que tenga conocimientos básicos de antropología sabe que no existe una sola definición de 'cultura' y que incluso al interior de dicha disciplina la utilización del concepto resulta problemática en tanto que su significado depende de la 'tradición de pensamiento' a la cual uno se acerque. Y por mucho que uno 'hurgue' en los libros clásicos de antropología, no se va a encontrar con tan estrambótico concepto: narcocultura. El inventario y las posibilidades de uso del adjetivo 'narco' en una sociedad como la nuestra (emblemática por el 'tráfico ilegal de estupefacientes' y todo lo que ello conlleva), son casi inagotables. Esto de la narcocultura en realidad parece ser más un invento periodístico que un concepto antropológico. Concepto que atrapó, con el paso del tiempo, a una manada de investigadores y 
estudiantes incautos ávidos de demostrar, con datos, de qué estaba hecha esa tan mentada narcocultura. En los medios de comunicación y, ahora, en los libros y algunas revistas 'respetables' de corte académico, el concepto se ha introducido de forma poco convencional, pero bastante eficaz. Pocos han puesto en duda la validez, no de su uso, sino de su existencia. Pero esto en buena medida se debe a los medios de comunicación pues a diario nos atiborran con exóticos neologismos. Una de las cosas más terribles es que ya existen tesis de psicología social sobre la denominada narcocultura.

Sólo imagine que su padre fuese un narcotraficante, usted sería su narcohijo y su madre sería una narcoesposa y la silla predilecta de su padre una narcosilla (¿en qué se diferenciaría una silla convencional de la silla del narcotraficante?, hasta donde este tipo de razonamientos 'eficientes' nos guían, sólo se diferencian una y otra en que la usa alguien que 'trafica' con drogas y, por ende, la conclusión es más simpática ahora, pues la silla que usted usa podría ser una sociosilla en caso de que usted sea un sociólogo o una antroposilla si usted es un antropólogo o una econosilla si usted es un economista). ¿No es un tanto absurda esta situación? Demasiado podríamos decir. Razón por la cual hay que tomar las 'modas culturales' con cautela. Hoy en día, por ejemplo, incautos investigadores y estudiantes se han autodenominado 'narcólogos', terminacho que debe definir a un conjunto de 'especialistas en temas relacionados con el narcotráfico'. Su utilización no es inocente pues de alguno u otro modo 'profesionaliza' el quehacer de estas personas interesadas en el tema del 'narcotráfico'. Y si se pone atención a este fenómeno será fácil dar con los sexólogos, los preventólogos, los tanatólogos, etc. ¿Cómo deberíamos llamar a la 'cultura' propia de las personas que venden hot dogs en las esquinas de las calles? ¿Ellos no poseen el capital cultural de los narcotraficantes o su 'realidad' no es tan importante como para hacerse merecedores de una subcultura ni de un conjunto de expertos que los entrevisten y los conviertan en celebridades del mainstream de la psicología social?

Podemos decir entonces que existen terminachos no científicos que, por su uso popular y bastante extendido, dan lugar a 'temas de investigación' que, con el paso del tiempo, se aceptan como 'realidades materiales' y, obviamente, objetos de estudio. Las personas que 'trafican' con drogas ilegales existen, es cierto, sería una locura negarlo, pero de ahí a que tengan una 'cultura propia', es muy distinto. Si la narcocultura existe y es una realidad material, entonces ¿por qué no inaugurar líneas de investigación sobre la gerontocultura, la paidocultura, la servilcultura o cualquier otra cosa que a uno le venga en gana? De cualquier modo parece que la gente, hoy en día, está ávida de neologismos cautivadores mientras que los investigadores están desesperados por escribir libros y ensayos para revistas sobre 'nuevos temas' que les permitan ganarse la vida. Estos investigadores también se muestran deseosos por generar presupuestos para hacer turismo académico hablando de sus 'nuevos temas' dentro y fuera de su país de origen.

\section{Evaluar: ¿intercambiamos cuestionarios?}

Otra consideración tiene que ver con dos aspectos centrales en el momento de investigar. El primero es que no sólo "es difícil realizar observaciones fiables a causa de la incapacidad para emitir juicios valorativos; y entonces nuestras observaciones se hacen más simples o se vuelven confusas o ambiguas" (Blumer 1981:138), sino que es imposible. El segundo es que "si limitamos nuestra observación a los actos físicos, lograremos reunir datos sólidos, pero tendríamos que preguntarnos: ‘¿para qué?' " (Blumer 1981:138). Por lo regular se pasa por alto que existe una especie de sesgo prescriptivo tanto en la teoría como en la práctica psicológica. Es cierto que: "al generar conocimiento acerca de la interacción social, comunicamos también nuestros principios personales. El destinatario del conocimiento recibe, así, un 
doble mensaje: por un lado, se le describe desapasionadamente lo que aparentemente son las cosas y, por otro, sutilmente se le prescribe lo que es deseable" (Gergen 1998:39).

En otras palabras: no podemos abstraernos de la realidad y ponernos 'al lado' de ella (Ibáñez 2002:35). Debemos tomarnos muy en serio el hecho de que describir, inevitablemente implica 'evaluar'. Realidades o personas. Para el caso es lo mismo. ¿Podemos evitarlo? La respuesta es muy sencilla. No, pero lo que sí podemos hacer es "evitar disfrazar los conceptos como reflejos objetivos de la verdad" (Gergen 1998:42), y como realidades concretas. Del concepto 'acoso escolar' a la parcela de realidad que supuestamente define dicho concepto hay un tramo largo de evaluación y prescripción. Un trabajo de definición y construcción. Y no un conjunto de evidencias empíricas que certifican la validez del concepto. Ni tampoco un conjunto de elementos conceptuales que certifican la existencia de dicha realidad material.

El segundo aspecto, que tiene que ver con los datos y su naturaleza, nos tiene que llevar por fuerza no sólo a preguntarnos ¿ ¿ara qué los queremos? sino ¿cómo los estamos reuniendo?, es decir, ¿cómo los estamos construyendo? La "cientificación" de la conducta implica que "al tratar de explicar los comportamientos indeseables, los psiquiatras y los psicólogos dieron origen a un vocabulario técnico de las diferencias que se fueron difundiendo entre el público en general, de modo tal que todo el mundo se ha vuelto consciente de los problemas de la salud mental" (Gergen 1993:34). Dicha "cientificación" de la conducta está relacionada, aunque no se aprecie claramente, con una producción indiscriminada de datos provenientes de las universidades o centros académicos donde se imparte psicología y psicología social. La práctica de aplicar cuestionarios entre los estudiantes está bastante arraigada, difundida y legitimada como forma de hacer investigación. Los estudiantes y muchos investigadores construyen 'instrumentos de medición' de la conducta sin preguntarse ‘¿para qué quiero esos datos?’ Así, se puede ver a estudiantes diciéndose unos a otros "mientras respondo tu cuestionario tú me respondes el mío". Dichos datos, por lo regular, no se sistematizan. Y no sólo eso. Cuando se generalizan las afirmaciones que se obtienen de dichos trabajos de investigación, se piensa que pueden aplicar por igual a cualquier habitante del planeta. Sin importar las diferencias culturales o ideológicas. Si dichas afirmaciones vienen de Cambridge o Harvard se asumen como incuestionables. Es bastante interesante mirar en los noticieros de la televisión o leer en periódicos y revistas que en los distintos centros universitarios donde se imparte psicología, en países del primer mundo, se ha llegado a distintos hallazgos en materia de investigación. Si dichas investigaciones se realizan con estudiantes o ratas, quiere decir que más o menos pensamos como los estudiantes de dichas universidades o como ratones mejorados genéticamente, pero de primer mundo.

Los datos que se producen en las investigaciones de corte universitario tienen el mismo destino que un pañuelo desechable. Su objetivo no es precisamente el de cumplir con un fin de investigación, sino de coadyuvar al estudiante o al investigador en la consecución de un objetivo distinto que el de investigar, como puede ser la titulación o la publicación de un reporte. Situación que le redituará en 'puntos' académicos que quizás se conviertan en becas o dinero en efectivo. Es decir, se producen datos no con la finalidad meramente de investigar sino de titularse o de publicar. La producción de datos como tal se convierte entonces en un medio para alcanzar un objetivo que no es académico sino burocrático.

Esto tiene que ver con esa bella pregunta ¿qué mueve a las personas a investigar? Si es la titulación o la publicación, entonces la actividad de investigar adquiere un tinte burocrático. Se investiga por razones extra académicas. Se investiga porque se tiene que hacer. Se toma a la investigación como un medio para conseguir algo que se sitúa más allá del propósito mismo de investigar. Por ello existe un sinfín de académicos peleando presupuestos y financiamientos por todas partes. Y claro que no se puede hacer investigación sin financiamiento, pero es muy distinto el propósito que mueve a un burócrata de la 
investigación que el que mueve al que investiga por placer. Muchos hacen investigación con el propósito de adquirir la fama que podría tener un rockstar, sin embargo, para su desgracia, difícilmente podrán llegar a ser como Bob Dylan o David Bowie. No se puede investigar con la pretensión de ser famoso. O ser rico. Entre tanto remolino, claro está, también hay quienes investigan para enriquecerse y cobran sumas exorbitantes de dinero por asesorar proyectos. El investigador está comprometido no sólo a preguntarse ¿para qué quiero esos datos?, sino ¿cómo los construyo?, pero sobre todo, ¿para qué hago investigación?

\section{Construir realidades}

La tercera consideración y última contenida en este texto, aunque existan más, tiene que ver con una peculiaridad de la psicología social en términos del uso social de sus conceptos. No es antes, sino hasta que los estudiantes de psicología social se topan con algunas clases de psicología experimental que caen en la cuenta de que la 'disonancia cognitiva' existe y es real. Y después se convencen entre ellos mismos que han experimentado dicho ¿sentimiento?, ¿emoción?, ¿proceso? Es fácil escucharlos decir entre los pasillos "estoy en disonancia". Experiencia a la que no está expuesta ninguna persona común. Sus abuelas seguramente jamás experimentaron la famosa 'disonancia cognitiva'. Ni la van a experimentar. En 1973, Heinz von Foerster afirmó: "Recuerdo hará unos veinte años, cuando algunos de mis amigos vinieron a verme, encantados y pasmados sobre un gran descubrimiento que acababan de hacer: 'iVivimos en un medio ambiente, hemos estado viviendo toda nuestra vida en un medio ambiente, sin saber de él!' [...] en cuanto percibimos nuestro medio ambiente, nosotros lo estamos inventando" (Foerster 1994:38).

Quien después de cuarenta años se da cuenta de que habla en prosa, cae en la cuenta de que toda su vida ha estado hablando en prosa. No es pues que el conocimiento transforme la realidad, sino que el conocimiento transforma nuestra forma de relación con el mundo y nuestra forma de relación con las demás personas. Incluso con nosotros mismos, aunque esto no se da de manera automática. El filósofo y lógico británico Bertrand Russell sostenía que "a menudo es más fácil determinar si una creencia es útil que determinar si es verdadera" (1966:173), en tanto que la utilidad es un criterio y que la utilidad no garantiza el significado de la verdad, aunque solemos suponer que es así. La existencia de una creencia, siguiendo el razonamiento de Russell, es un hecho y, por tanto, no puede ser verdadera o falsa. Lo que puede ser falso es que dicha creencia justifique la existencia de algo que simplemente no tiene existencia. Por ello no podemos pasar por alto la distinción "entre creer en la existencia de algo que existe y creer en la existencia de algo que no existe" (Russell 1966:180). De tal modo que podemos afirmar que la existencia de la creencia no garantiza la existencia de aquello en lo que se cree. Y eso en lo que se cree puede ser la disonancia cognitiva, el inconsciente o Dios. Están hechos del mismo material que es el lenguaje. No obstante hay que hacer una precisión. Y es que "en la creencia hay una gradación continua; y cuanto más firmemente creemos en algo, menos dispuestos estamos a abandonar la creencia en caso de conflicto" (Russell 1966:182).

En el centro del debate de esta última consideración está pues la revisión crítica de los conceptos propios de la psicología social. Uno podría preguntarse ¿dónde están esos hombres de los que parten los enfoques motivacionales que retornan feliz y naturalmente a un equilibrio cognitivo después de superado el conflicto? ¿Dónde están esos hombres de los cuales nos hablan los enfoques motivacionales cuyos conflictos 'intraindividuales' jamás ascienden a un siguiente nivel, sino que se mitigan tan fácilmente enarbolando las cualidades de su elección y despreciando aquellas por las que no se optó? El problema de la revisión crítica de los conceptos es fundamental en tanto que las realidades que crean no son independientes de quienes las definen. Es decir, la realidad en la que vivimos no es independiente de nosotros como suponen los positivistas. 


\section{Consideraciones finales}

Una pregunta, en medio de todas estas complicaciones, es clara y, para muchos, quizás devastadora o incómoda. ¿Cuál es el 'impacto real' de las investigaciones de la psicología social en las sociedad? ¿Le ocurre algo a la sociedad -para bien o para mal- cada vez que un psicólogo social o un puñado de ellos culminan una investigación? ¿Y a las personas que viven en ellas? Siendo sinceros todo parece apuntar a que no es así: "Estamos en un mundo con Psicología Social. Imaginemos ahora un mundo donde la investigación psicosocial no estuviera presente, donde ésta no existiera. Un mundo sin. ¿En qué se diferenciarían un mundo con y un mundo sin? Un mundo sin alcohol sería sin duda distinto, un mundo sin literatura sería sensiblemente diferente, un mundo sin investigación física sería radicalmente otro, pero mucho me temo que un mundo sin Psicología Social sería sustancialmente el mismo que un mundo con, salvo para algunas generaciones de estudiantes universitarios que han visto cómo se cruzaba la Psicología Social en su camino, para algunas editoriales que deberían refundar sus catálogos y, por supuesto, para quienes hemos hecho profesión de esta disciplina" (Ibáñez 2002:32).

¡Qué falta le hacen los disidentes a la psicología social en un tiempo en que nuestra disciplina sigue dominada por aquellos quienes pretenden predecir y controlar no sólo el comportamiento humano, sino la producción del conocimiento! ¡Qué falta le hace un espíritu crítico a la psicología social que podría ser menos 'canónica' y más amable! Una de su crisis más profunda es que mientras sus teorías apuntan hacia una dirección, lo que está ocurriendo en la realidad inmediata se mueve en otra dirección, pero, sobre todo, sus conceptos no alcanzan más que para describir, pensar, explicar, problematizar, etc., diversos fenómenos que tienen ocurrencia en el mundo contemporáneo. Sus conceptos se desgastaron y no parece haber unos nuevos.

\section{Notas}

(1) La conspiranoia, según el ilustrativo texto de Mark Dery (1999), alude a la creencia de que todo tiene un significado, de que todos los cabos aparentemente sueltos de la historia están entretejidos en una oscura red cósmica. Que el complejo diseño de esta red mundial sólo es conocido por los conspiradores invisibles que en secreto tejen nuestra realidad.

(2) Para ampliar información se puede visitar el siguiente sitio: http://www.observatoriolaboral.gob.mx/swb/es/ola/Top_10_de_carreras

(3) Dos textos son los que se suelen considerar como los primeros manuales de psicología social: Social Psychology de E. A. Ross junto a Introduction to Social Psychology de W. Mc Dougall publicados en 1908.

(4) En el marco del Foro Mundial Evaluando Resultados de los Programas de Apoyo a Becas de Posgrado de México, el coordinador de dicho foro ofreció estas cifras. Para tal efecto se puede consultar: http://www.foroconsultivo.org.mx/innovacion.gaceta/component/content/article/149-foros-del-

foro/196-solo-16-de-cada-10-mil-mexicanos-estudian-un-posgrado

(5) Con el objetivo de ampliar la información se puede consultar esta nota del periódico La Jornada: http://www.jornada.unam.mx/2011/05/22/sociedad/036n1soc

(6) En este contexto se podría interpretar como "las corrientes principales de las modas académicas de la disciplina".

(7) El uso de esta expresión alude a las tendencias principales de la disciplina. 


\section{Bibliografía}

Billig, M. 1987. Arguing and thinking: a rhetorical approach to social psychology. Cambridge: Cambridge University Press.

Blumer, H. 1981. El interaccionismo simbólico. Barcelona: Hora.

Bourdieu, P. 1973. El oficio de sociólogo. Madrid: Siglo XXI.

Collins, R. 2005. Cadenas de rituales de interacción. Barcelona: Anthropos.

Dery, M. 1999. The pyrotechnic insanitarium: American culture on the brink. New York: Grove Press

Eco, U. 1984. La estrategia de la ilusión. Barcelona: Lumen.

Alvaro, J.L. y Garrido, A. 2003. Teoría sociológica y vínculos psicosociales. En: Álvaro Estramiana, J.L. (ed.) Fundamentos sociales del comportamiento humano. Barcelona. UOC, pp. 45-110.

Foerster, H. 1994. Construyendo una realidad. En: P. Watzlawick (Ed). La realidad inventada. Barcelona: Gedisa, pp. 38-56.

Gergen, K. 1993. El yo saturado. Barcelona: Paidós.

Gergen, K. 1998. La psicología social como historia. Revista Anthropos 177: 39-49.

Ibáñez, T. 2002. ¿Fondear la objetividad o navegar hacia el placer? Athenea Digital 0: 31-37.

doi: $10.5565 / \mathrm{rev} /$ athenead/v1n0.3

Onfray, M. 2010. Freud: el crepúsculo de un ídolo. México: Taurus.

Russell, B. 1966. Ensayos filosóficos. Madrid: Alianza.

Verdú, V. 2005. Yo y tú, objetos de lujo. Barcelona: Debate.

Recibido el 13 Sep 2014

Aceptado el 25 Nov 2014 